\title{
Information Technology in Healthcare: HHC-MOTES, a Novel Set of Metrics to Analyse IT Sustainability in Different Areas
}

\author{
Marco Remondino ${ }^{1,2}$ (iD \\ 1 Department of Economics, DIEC, University of Genoa, 16126 Genoa, Italy; \\ marco.remondino@economia.unige.it; Tel.: +39-346-217-4311 \\ 2 Institute of Management, Sant'Anna, University of Pisa, 56127 Pisa, Italy
}

Received: 28 June 2018; Accepted: 30 July 2018; Published: 2 August 2018

\begin{abstract}
Sustainability, as a science, is the guideline of the present work. It aims to analyse, by means of a literature review, various areas of healthcare in which information technology (IT) has been- or could be-used, leading to several sources of sustainability, for example, cost savings, better teamwork, higher quality and efficiency of medical care. After a brief introduction analysing the strategic contexts in which innovation in general, and IT in particular, can be a source of general improvements in efficiency, cost savings and service quality, the research focuses on the healthcare system by discussing the different nature of private and public organizations in terms of adopting innovations and changes and discussing the issue of consumer health costs and consumer choices. The following part focuses on the qualitative benefits of IT in healthcare and discusses the importance of metrics for measuring performance, costs and efficiency in this area. The work then qualitatively introduces a new set of Key Performance Indicators (KPI), partly based on literature from different topics and existing and validated sets of metrics, analysing, under the point of view of sustainability, the implementation of IT in healthcare, namely in management, organization, technology, environment and social fields (HHC-MOTES framework). The model, inspired by and to sustainability, can be used as a decision support at the strategic management level as well as for the analysis and investigation of the effects of IT systems in the healthcare sector from various perspectives.
\end{abstract}

Keywords: information technology; healthcare; measurement; efficiency; performance; managerial perspective; key performance indicators; decision support; HHC-MOTES framework

\section{Introduction}

Sustainability in different fields-namely: managerial, organizational, technological, environmental and social—is the guideline of this research, which concerns the impact, on these areas, of the adoption of IT in healthcare and presents a new set of metrics for the evaluation of this specific issue.

In particular, this work is based on a trans-disciplinary literature and perspectives, which mainly cover the topics of:

- new technologies (specifically IT) for healthcare sustainability, from different perspectives

- qualitative measures of sustainability for healthcare organizations, related to the introduction of IT (the novel HCC-MOTES framework)

- systems management for sustainability in healthcare organizations, in relation to the different but interconnected areas, affected by the introduction of IT.

The framework also aims to provide a decision support tool for health management, with a particular focus on IT in this specific area. 
In both public and private companies, there is a constant need for ongoing assessments of core activities and processes in order to better monitor policy progress and learn from past challenges, problems, mistakes and experiences. More and more institutions are examining how information systems can help them achieve their desired goals.

Organizations that need to consider whether or not to adopt a particular innovative technology, need to rely on a cost-benefit analysis [1-3], especially when a radical redesign of the process is needed. The analysis has, obviously, to take into account economical endogenous aspects, like financial ones, but, in a wider vision of sustainability, also other aspects have to be considered, like, for example, social, ethical, technological and environmental ones [4-6].

Innovation is defined [7] as the creation of something that does not yet exist, for the use of new products, for more efficient processes [8], new services or ideas and is therefore associated with change [9]. Innovation is considered one of the most important elements for any organization, whether public or entrepreneurial, with the objective of competitive advantage [10]. When dealing with a particular critical situation arising from external or internal elements of an organization, a powerful way to deal with it is to drive and promote the change [11].

The use of performance measurement parameters is essential to evaluate activities and to determine the most efficient actions required to achieve the desired goals [12-15].

In $[16,17]$ it is possible to find evidence of how innovation is often linked to the concepts of sustainability, economically, ecologically and socially. In dealing with public organizations, as is often the case with health systems, sustainable development requires the promotion of revolutionary technological innovations through environmental, health, safety, economic and labour market regulation [18].

There are various sources from which innovations can emerge, some from individual creative efforts such as inventions, others from users of certain technologies looking for solutions that better meet their needs [19]. Some sources of innovation may be internal or external to the organization, depending on whether activities are organized by internal research and development (R\&D) departments, external sources such as universities or liaison offices, set up specifically to promote the transfer of innovative applications to markets $[20,21]$.

Information technology (IT) is described as the collection, processing and storage of data by a computer-based product [22], while Information and Communication Technology (ICT) is a term that adds a third dimension to IT, by integrating telecommunications along with computers and data management software, to enable users to store, manipulate and transfer information from one point to another [23-25]. Both IT and ICT are often regarded as innovative when applied to businesses and organizations $[26,27]$, since they tend to deeply change the way in which resources work, enterprises compete and since they usually require some sort of process reengineering [28,29]. IT has been linked with the concept of sustainability (whether ecological, ecological or financial) within organizations, in for example, [30-33] and the concept is in constant development and of great scientific interest [34].

One of the most compelling challenges to managers and business administrators is to dispose of valid tools to efficiently manage resources, coordinate services, share/exchange ideas, knowledge and know-how across an organization, or within interconnected institutions, in order to properly respond to social needs [35,36]. IT systems are seen as particularly useful for administrators to understand the millions of pieces of information that companies collect every day to manage operations [23].

However, IT usage assessments in business practice force companies to rethink working methods and procedures, sometimes by thoroughly reviewing activities and processes that appear outdated and are no longer sufficient to meet future expectations [29]. These changes, which require a radical change in working habits, bear the name Business Process Redesign (BPR). Examples of the reorganization of business processes are the radical revalidation of decision-making roles [37] and of management board [38], the acquisition and dismissing of business functions [39] and the adoption of new working methodologies [40].

The purpose of this research is twofold. On the one hand, it is a question of analysing the state of the art for IT introduction in the healthcare system [41] with special attention to the stakeholders involved 
and the benefits for them in the broader sense of sustainability. In particular, social sustainability is a very important issue for healthcare and the social benefits can be assessed by analysing the impact of the organization on stakeholders at local, national and global levels [42,43]. Issues related to health care costs for consumers are also compelling, along with the topic of consumers' choices and behaviour [44], especially for developing countries, where IT applications can help solve many problems directly related to reducing treatment costs (information and data costs) [45].

On the other hand, this paper presents a novel set of metrics and KPIs, the HHC-MOTES framework, which is intended for the qualitative and possibly quantitative measurement of the various aspects related to sustainability, in the broader sense, of IT applications in healthcare. While some of these KPIs are derived from existing literature and validated sets [46,47], the novel framework presented in this work was conceived as comprehensively as possible, in relation to this specific field. However, with some adjustments, it could also be applied to other areas and situations, where IT can be seen as a source of innovation, efficiency and sustainability.

The main objective of the presented framework is to bring together literature from very different areas and bridge it into a model that describes most areas in which the sustainability and efficiency of an IT system can be evaluated in the context of health care.

The model can primarily be used as a decision support tool at the strategic management level, by helping to select and develop several performance indicators in different areas, according to specific strategic objectives, inspired by and to sustainability. In healthcare, it is not enough to take financial aspects and customer satisfaction into account. It is also important to assess the social aspects, which are becoming increasingly important, especially—but not only-in developing countries (access to medicines, costs to consumers), the environmental aspects and those related to the internal organization and efficiency of hospital facilities. When evaluating IT results, two categories can be distinguished: a short-term cost-benefit assessment, which is often used for individual projects and a long-term assessment, which is more complex because it covers both the IT application and the department (or organization) as a whole. The HCC-MOTES framework aims, in particular, at the second category, by partially evaluating the specific cost-benefit assessment of the information system itself but rather concentrates on its impact on the organization (endogenous), stakeholders (endogenous/exogenous) and the environment (exogenous).

Since quantitative testing of the framework has not yet been carried out, the implications are largely theoretical but the model can already provide guidance for healthcare policy makers and stakeholders, for example, in the selection of the right information systems and/or in improving existing systems and/or in the search for limits or competitive advantages and/or in the selection of areas to be prioritized.

\section{Healthcare System Overview and Performance Indicators}

The health service is defined $[48,49]$ as the combination of the functions of public health and company medical services, while the health systems cover all the different activities guided by a common goal, namely the improvement of health outcomes for all people in the health chain through the provision of medical services.

National health systems can be financed through public participation, with reference to the participation of national or regional governments, or managed by private institutions such as insurance companies. Market-based systems are widespread in the US [50,51] and are based mainly on individual private health insurance to finance services, while tax-financed systems use general tax revenues to finance healthcare and are more frequently administered by national and regional governments. The aim of the tax-financed systems is to give all citizens equal access to health services, since they contribute directly to the payment of the services they provide. Such universal health systems are widespread in EU countries [52] and Canada [53].

When resource allocation is determined by market forces, the result is as close as possible to perfectly competitive markets. However, most health systems are characterized by the broad 
participation of national and regional governments, as no market works perfectly, in most developed countries [54]. Public institutions tend to have a greater responsibility than private organizations [55] and therefore fight harder for the correct application of contractual provisions, to avoid any kind of opportunistic behaviour that could harm the Community [56]. In this context, performance indicators [57] are essential to obtain an overall picture of health outcomes and to provide opportunities for benchmarking [46] that rationalize resources in the context in which organizations operate. It is the task of public health organizations to plan and define strategies that maximize resource productivity, respond appropriately to people's health needs, priorities projects and action plans, develop new services or transform inefficient ones while ensuring a high level of quality for citizens. In contrast to private companies, public companies must be cost-efficient [58] although they do not necessarily have to strive for profit, because, for them, profit is not a goal to be achieved but a characteristic that helps organizations to achieve their actual goals [59].

Health systems in different EU countries reflect a variety of heterogeneous approaches, each with its own particularities. EU countries are focusing their strategies on innovations in the health process, which are seen as essential for improving results. The aim is to respond to the recession by seeking more efficient solutions for affordable and sustainable healthcare and to potentially direct the markets towards the creation of new services for the treatment of needy patients.

In this context, healthcare policy makers are aware of the gap in the European use of IT and have therefore decided to develop common strategies for e-Health (as the commitments made by national and regional governments in each country, to improve healthcare systems through the use of the Internet and ICT), to contribute to reducing the gap within the EU by promoting ICT-based systems. [60,61]. The main objectives of the European e-Health Action Plans concern the introduction of interoperable information systems, such as the electronic medical records (EMR) [62,63].

Indicators can be used to measure the degree to which objectives have been achieved, changes happen and effects are obtained, as they provide quantified information, useful in supporting decision-making processes. The ability to compare data on strategies and performance of different healthcare facilities at a regional, national and international level is recognized as an essential element in identifying weaknesses and threats to the internal system and defines the most appropriate strategies to improve outcomes.

Since current market conditions encourage actors to promote collaborative approaches, in spite of competitiveness, this leads to the need for healthcare facilities to provide parameters $[64,65]$ to benchmark activities and compare results to assess the need to take corrective action on pre-defined strategies. In addition, the use of qualitative and/or quantitative parameters activates learning processes that lead to the acquisition of best practices.

Researchers have shown [46] that countries that have fragmented control over their national healthcare systems and where each provider pursues individual goals, are obviously a consequence of negligible integration, low information exchange and reduced acceptance of healthcare IT systems, leading to poor and inadequate performance levels measured by metrics. These observations underline the importance of cooperation between actors in the healthcare chain, such as governments, institutions, hospitals, doctors, employers, pharmacies, consumers and other health subjects, that need to work towards common goals, to increase the chances of success.

However, empirical evidence shows that, in several countries, there is a highly isolated development of technological progress that occasionally offers isolated and individual innovative solutions for medical treatment, while the recent strong competition within the IT industry unintentionally leads to an overall effect similar to that of economies of scale, reducing the cost of high-tech products and services and making them more affordable and accessible than ever before. $[46,66]$.

As a notable example in introducing performance measurements for healthcare, efforts were taken by the Laboratory Management and Health of Sant'Anna (Pisa, Italy) to define a new multi-dimensional set of KPI of health [46], initially adopted by the Tuscan Region, Italy $[67,68]$ and later expanded to other 
Italian Regions such as Liguria, Piedmont, Umbria, Valle d'Aosta, Marche, Basilicata and integrated within the public administration of Trento and Bolzano [69].

In this model, various macro-dimensions of KPIs were identified, taking into account: population health status, social and health evaluations, external and internal assessments, as well as operational efficiency and financial and economical assessments.

It is worth noting that the benefits tend to increase as the KPIs currently adopted by some Italian regions such as Tuscany, Liguria, Piedmont, Umbria, Val d'Aosta, Marche and Basilicata should be disseminated at a national or, better, at an international level, in order to achieve common methods and parameters for evaluating performance and to enable benchmarking.

\section{IT in Healthcare: Network Infrastructure Benefits, Interrelations between Providers and Costs for the Consumers}

The answer to major EU e-Health objectives is to be investigated in increased collaboration between health and social care organizations, through which it is possible to reach integration of systems for efficient communication and information processing [70]. Interoperability between these systems can only be guaranteed if different health professionals are prepared to cooperate actively with each other, highlighting the content relevant to them, in patient records.

Integration processes are found to improve equity of care while preserving previous investments taken at the same time [71,72]. Equity goals in health [73] may prevail efficiency goals in the short run, since granting a wider health coverage implies delivering equal medical treatment for marginalized groups of people, as well as for citizens residing in isolated areas, which is known to be particularly costly for healthcare structures [74].

New technologies are initially developed to fulfil specific needs-such as efficiency improvementsor to create new markets. Whatever the purpose, the managers' intention is to invest resources and money to develop specific technologies that can prove to be dominant designs for competitors within a given timeframe. The reason for the desire of convergence towards a single model and not to promote competition between technological products, lies in the higher returns associated with the increased use of a particular technology and in the reduction of IT costs, due to economies of scale. For markets linked to network externalities, the benefits of using products tend to increase in proportion to the number of users of the same product [75]. Benefits tend to increase along with increments in the number of users, especially when compatibility is an essential factor and interactions with common standardized languages of communication are requested [19].

The modulatory feature of IT applications facilitates the customization of environments according to users' need. Such systems enable hospital facilities to store large amounts of data for treatment purposes, evaluations and as support systems for correct decision-making. By using EMRs, healthcare providers can better monitor patients' health status, undertake better evaluation processes, pinpoint the presence of wastes within certain health sectors, avoid redundant services, ascertain the existence of unnecessary resources, or the lack of needed resources for particular treatments and, above all, help users navigate through a more efficient health system [76,77].

Many basic integration processes have taken place across Europe, particularly at local or district level, some of which have focused on data exchange between actors from different sectors [78]. A consistent amount of data exchanged between stakeholders reduces most problems related to the development of individual separate systems, such as data storage costs, hardware and software costs, as well as personnel costs.

The ability to retrieve required data from a central database system reduces the idle time associated with data transfer between agencies or departments, as they can access the desired information in real time, independently of each other, without each individual provider having to buy expensive physical storage space. Essentially, this would also facilitate cooperation between geographically separate medical operators, as they would have the possibility to create medical patient reports remotely [79] and to store the data only once within the central system and to enable future access to 
the patient's medical history. However, to get this system up and running efficiently, it is necessary to define standardized communication protocols that reduce the risk of obtaining fragmented and futile data that would instead result from errors in achieving high levels of integration between multidimensional networks.

In addition to multidimensional IT models, other types of interoperable systems, relating to individual access points, are also being tested. In contrast to previous systems, they tend to minimize the number of access channels of providers to a single point. This inevitably affects the structural dimension of organizations, professionals and resources in the system, as users are called upon to interact with a significantly smaller number of elements. The Spanish region of Valencia [80] has initiated integration processes in the healthcare sector with the support of external private providers. Outsourcing the management of innovation processes to experienced providers has enabled the creation of incentives that have strengthened integration and led the hospitals in the region to positive results in terms of quality and efficiency, not to mention the development of new cost-effective health procedures for the treatment of diseases.

Other examples of successful innovation models (among many) include the Aarogyasri healthcare Trust in India [81], a programme aimed at bringing professionals together and learning from each other, to facilitate knowledge transfer and information exchange and develop best practices for efficient healthcare procedures. With the establishment of the Health Management and Research Institute (HMRI), the Indian government wants to sustainably improve its healthcare system and achieve some of its most ambitious goals, namely access to health care and coverage for the entire population. The sound cooperation between medical staff from various medical departments and health organizations, both at national and international level, initially ensured that the system design meets the essential requirements for the complete electronic storage of patients' medical information, so that those involved can immediately benefit from the advantages of these new technologies. In addition to the cost savings due to the concentration on the essentials and the associated time savings in development, further advantages were achieved above all through the automation of administrative activities such as medical reports and discharge procedures, which led to consistent time savings for the staff.

The availability of patients' medical data [82] drives the delivery of health services out of hospitals and into community care centres, which may result in better qualitative and most effective healthcare treatments for users. Furthermore, users may perceive greater benefits from decentralized models as local authorities have more opportunities to establish personal and more confidential relationships with patients.

Health IT applications rely on a few basic requirements, needed for their implementation. That is: disposing of a main telephone line over which data or message alerts can transit and reach doctors within the infrastructure; a software application that is able to acquire, process, store and transmit patient information in real-time, which is gathered digitally from sensor devices [83]. The software application allows the definition of standard protocols for wireless communication, inside and outside hospitals. Finally, the use of sensor devices worn by patients to record, process, store and transmit the physiological health values of users.

Regarding the costs $[84,85]$, initial expenses are adduced to hardware and software components, other expenses for the physical implementation of the system, while further costs are due to licensing and system maintenance, without mentioning the cost for missing alternative investment opportunities and the time spent by technicians, physicians and specialists in formation to learn how to correctly use the new system, instead of visiting patients.

Being able to access patients' summary files helps hospitals reduce costs and increase efficiency, as it prevents physicians or specialists from duplicating diagnostic examinations recently performed by patients. Moreover, it allows healthcare providers to access in real time the medical records of the various health departments, enabling automatic transmission of urgent clinical information across the health network at national level, for diagnostic results or medical treatment practices ordered by 
physicians and GPs, or for sending digitized images from radiological units via RIS/PACS applications. In addition, it enables the patient to be seen adequately by the specialist and to transfer the results and referrals immediately to the family doctor for an adequate therapeutic disposition.

The savings from EMRs are not only related to paper costs, or to the time spent by medical staff in filing and searching for folders but also cover the cost of large storage space required to store patient medical record printouts over time. Further benefits arising from the use of computer-based information applications in hospital facilities include the alert feature, which enables various health departments to access new guidelines and procedures cost-effectively, as well as providing the feedback to doctors and specialists on the quality of the services they deliver, which can be compared with national and international performance indicators in order to measure the degree of competitiveness of the internal system.

Storing patients' medical information in electronic databases can also be very useful for hospitals and local health centres to reduce medical errors by preventing doctors from administering erroneous drugs, medications or therapies to users. Computerized Providers Order Entry (CPOE), which is a part of EMR, enables the sharing of large amounts of data to be accessed by different providers, accelerating treatment processes while improving medical services to better meet individual needs. It is obvious that the reduction in the number of malpractice generates different positive returns, not only in terms of quality, or of users' perceived service but also in terms of reduced health expenditure, as demonstrated by the Freeman Hospital case.

A research conducted by the RAND Health IT Project team, reported that hospitals and local municipalities could achieve significant cost savings by installing CPOE applications. The analysis suggested that U.S. hospitals that introduced CPOE prevented 200,000 adverse drug incidents and saved over $€ 800$ million each year [86].

There could be many more examples of the use of IT in healthcare, such as bridging the digital divide between rural and urban health centres and addressing shortcomings in rural health [87] and, in general, reducing costs, promoting the exchange of health information and improving access to health care and public and personalized medicine, especially for developing countries [88]. The general consensus is that healthcare IT has the potential to reduce communication and infrastructure costs while improving teamwork and collaboration but also the portability of information and cares among different healthcare providers.

A compelling topic in healthcare is that of costs for the consumers; this is directly linked with IT, as several studies show, for example, [84,89]. IT is indeed linked to productivity growth in a wide range of sectors and in healthcare it is a leading example of innovation that can change productivity and efficiency. Several studies link personal factors with the propensity to spend on basic routine exams.

In [90], for example, it is suggested that job and marriage can increase the probability of participation to general health exam. Other works have shown how the trust in healthcare quality and health insurance coverage could influence the uptake of the mentioned exam [91]. A recent paper on health screening behaviour among Singaporeans similarly named low education and income levels as two factors associated with low uptake of periodic health exams [92].

A very interesting study analyses Vietnamese consumers' behaviour based on the specific "cost" variable [93]. Based on the results, the majority of respondents became very reluctant to pay for a health service equal to or above ninety US\$. The study also highlights a number of factors that could increase consumers' willingness to spend money in the health sector. As regards demographic factors, the survey confirms that people with different family and professional conditions have different views on health expenditure.

The issue of healthcare costs is particularly compelling in developing countries [94-96]. There is a risk of poverty and destitution in some countries, as a recent study shows [45]. In that paper, the authors identify four factors that contribute to increasing the likelihood of destitution for the Vietnamese population, namely: non-residency of patients (associated to travel costs and asymmetric information), high costs of treatment (which is the most significant factor), inadequate insurance 
coverage and the duration of stay in hospital. To this particular extent, IT systems and applications can help reducing the cost of information and data and to optimize the logistic part of healthcare, by reducing dead times, human errors and so forth [97].

Systematic reviews and evaluations of e-health implementations in developing countries have also shown that systems that improve communication between institutions, help in ordering and managing medicines and in monitoring and identifying patients who could discontinue treatment, are very promising [98].

Better IT strategies for the sector can also lead to positive development in cost reduction, not only in the specific healthcare sector but also in Science in general, for the developing world [99].

\section{A Novel Set of Metrics for IT Sustainability in Healthcare-The HHC-MOTES Framework}

As briefly discussed in the previous section, it is evident that IT usage in healthcare can bring positive results as to efficiency, financial sustainability and, more important, can bring social benefits in the form of increased quality of services and users' satisfaction, not to mention lower general costs for healthcare consumers. While quantitative metrics are beyond the purpose of the present work, they could be implemented in the model in a later stage of development. The fusion and partial integration of different sets of indicators are discussed in the following, in order to present a novel and possibly exhaustive set of KPIs to evaluate the sustainable development of IT projects specifically applied to healthcare. Performance measures usually focus on the extent to which something has been achieved, through the use of quantitative data only but not on how this is achieved or pursued. This may sometimes prove problematic or even non-exhaustive, as quantitative efficiency does not take quality into account. The framework theoretically proposed in the following can incorporate both qualitative and quantitative measures.

First, sustainability within healthcare system (HHC) is here considered for 5 main dimensions, namely the managerial/organizational, technological, environmental and social ones (MOTES). While these areas are analysed separately, they are intrinsically interconnected and an improvement in the efficiency of a specific area could, at times, influence other contexts. In general, these areas influence global parameters of the healthcare system, such as the costs of the service, its quality but also a better experience for the stakeholders (whether they are customers or employees of the healthcare structure) and environmental variables.

For the managerial/organizational KPIs, two areas are mainly influenced by the introduction of IT within organizations [100]. Those are the overall efficiency of organization, improved thanks to information efficiencies and information synergies [101] and financial performance, negatively impacted due to initial costs for IT implementation (and, in case, process reengineering due to change in procedures) and, later, potentially positively impacted by savings and improvements in overall efficiency $[89,102]$.

As for the technological dimension, sustainability performance can be analysed against a set of quality attributes [103,104], some of which are based on Jakob Nielsen's set [47], under three points of view-namely Development-Related, Usage-Related and Process-Related Properties.

As far as social KPIs are taken into account, those are partially derived from the already mentioned research of Sant'Anna [46], while others come from specific medical literature [105]. In the HHC-MOTES framework two macro categories are proposed, according to different stakeholders: the former, concerning social KPIs considered from the patient's side, the latter, comprising KPIs related to staff's side. Especially on the patient's side, the most notable examples are the collection of data about population health status and, even more important, the consequent reduction of medical errors, thanks to the storage of patients' medical information in easily accessible electronic databases. Also, the organized collection of data about patients' satisfaction and complaints, help to assess issues or weaknesses in the procedures and medical structures. Also, very important, is the time reduction to recognize a pathology and to treat it, again facilitated by patient's data and those about similar cases but also by the spreading of telemedicine and remote care [106]. 
Last but not least, a series of metrics about environmental measurements are introduced, mainly connected to the potential reduction of usage of physical resources (e.g., paper, space, transportation) and consumption of energy.

Managerial and Organizational:

- Organizational efficiency (length of stay at the hospital and bed occupancy)

- Financial effectiveness (financial measures for healthcare organization)

- Inter-operational synergies (possibilities to share data among different healthcare actors)

Technological (Development-Related):

- Modifiability/Changeability (the ability to make changes quickly and at little additional cost)

- Reusability (the level at which system components may be reusable for other systems)

- Portability (the system can operate in a variety of computing environments)

- Supportability (easy system configurability and linearity for subsequent maintenance)

Technological (Usage-Related):

- Performances (response time to user's requests)

- Reliability (ability of a system to function as expected at a given time)

- Usability (features that make the system easy and friendly to use)

- Accessibility (ability of the system to serve people regardless of location, experience, background, or the type of information technology used)

\section{Technological (Process-Related):}

- Efficiency (the overhead of production processes on the income value perceived by the customer) Social (patient's side):

- Monitoring of population health status

- Reduce costs for customers

- Patient satisfaction (with healthcare service, including satisfaction with physicians, waiting time, treatment and so on)

- Patient complaints (collection, processing, analysis and availability of data)

- Patient safety (Incidents/errors occurred in healthcare treatment process, including medication errors, diagnosis and treatment errors and so on)

- Average Waiting/Delay (the time required to recognize a pathology and/or to provide the necessary medical treatment

Social (staff's side):

- Employee satisfaction (with healthcare organization, with job, colleagues, supervisors and so on)

- Teamwork and multidisciplinary collaboration

- Overall work conditions

- Overall work efficiency versus efforts

Environmental:

- Consumption of energy

- Resources used in medical records (paper medical records, ledgers, rooms and so on)

- Resources used in healthcare activities and training (books, training rooms, paper and so on)

- Resources required to provide support (transportation, physical material and so on)

- Office space utilization and use of shared resources 
As highlighted in one of the following sections, this framework can be used by healthcare decision-makers to make strategic decisions about introducing or updating IT systems but also to examine current systems and identify limitations and shortcomings. The next Figure 1 is a scheme for the proposed model, in which it is clearer that the individual areas can influence each other and also the general costs for the service and other variables.

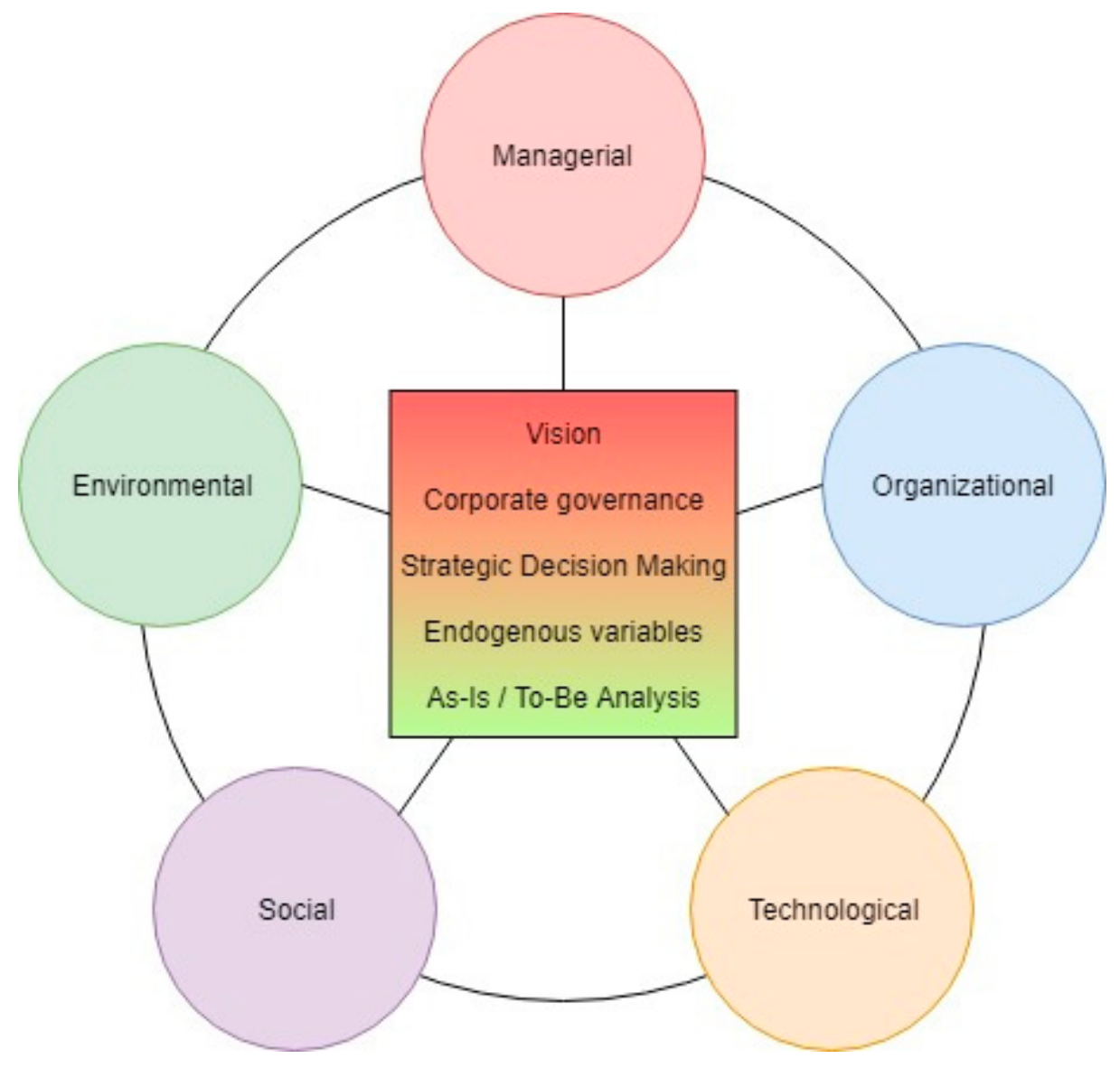

Figure 1. The synthetic scheme for HCC-MOTES framework.

\section{Discussion}

As to the managerial/organizational KPIs, the "organizational efficiency"-in general-refers to the degree of success in using the least possible inputs in order to produce the highest possible outputs. In the particular case of healthcare [107], this factor refers to the optimal usage of resources (both capital, human factor and physical items) and can be summed up as the relationship between a specific product of the health care system (also called an output) and the resources used to create that product (also called inputs). By this definition, a provider in the healthcare system (e.g., hospital, clinic, physician) would be efficient if it were able to maximize output for a given set of inputs or to minimize inputs used to produce a given output [108]. IT systems allow data to be organized and managed to increase organizational efficiency and strategic alignment within organizations [109].

As to the "financial effectiveness," it has already been pointed out that healthcare structures can be public or private. In this vein, the specific parameter could have different meanings in terms of sustainability [110]. Efficiency in finance means performing tasks in a timely and cost-effective manner, typically via simplified and standardized processes that leverage technology and consolidation/elimination of non-core activities through shared services/outsourcing. In other words, the factor of financial effectiveness refers to the evaluation of financial measures for healthcare organizations and the elimination of redundancies and waste and the possible outsourcing of activities that are considered as non-core [111]. 
As to "inter-operational synergies," this refers to the possibility of exchange information and data among different healthcare actors, structures and systems [112]. This is a crucial role for IT within healthcare [113] and an important source of sustainability, seen as the added value derived from the collaboration of different actors.

As to technological KPIs, they have been divided into three main categories, that is, those related with the development of IT system in healthcare, those related with its usage and, last, those that affect the process itself. It is important to notice that many of these KPIs are directly (or indirectly) connected with the already mentioned managerial KPIs, since most processes in IT development affect finances and efficiency of the organization. Nevertheless, some of these KPIs are worth analysing, as they relate to the core issue of current research.

On the developers' side, the KPIs are those typical for any IT platform, independently from the specific use, that is, modifiability, reusability, portability and supportability. The most interesting as to healthcare application is portability. As already mentioned, there are many different settings and scenarios in healthcare, hence the ability to use the same IT platform, with minimal changes, is important for both efficiency and costs. Furthermore, the issue related to the portability of EMR (outside the main system on which they were created) is important, since a patient could be receiving medical cares in different structures [114], so it has to be conceived as portable since the beginning.

On the user side, KPIs are more relevant to the specific case of IT in healthcare. The "performance" indicator, connected with the response time to users' request, is critical in a sector where a delay could cost the life of a patient. In both a traditional hospital and a telemedicine environment, physicians and patients need IT systems to react in real time and efficiently. The same applies the KPI "reliability," defined as the ability of a system to react as expected at a given time. "Usability" refers to the user-friendliness of a system; since healthcare operators are not computer scientists, the systems must be as simple to operate as possible, not requiring "ad hoc" knowledge to be used but the minimum possible. This issue has been described in detail in the literature, for example, $[115,116]$. Another very important indicator for IT in healthcare is "accessibility," which refers to the ability of the system to serve people regardless of location and other variables, such as experience and type of technological infrastructure. This is particularly important when referring to specific categories of people (e.g., elderly people $[113,117])$ or to developing countries (e.g., [118]).

The process related indicator, that is, the overall efficiency of an IT system, is, again, a generic KPI used in computer science. In this particular context it has an important role to play, since several processes in the healthcare domain can be reengineered, following IT introduction, even within the limits set by public service organizations and institutions [119]. This change must be taken into account by healthcare managers and presents them with new challenges but also new opportunities [120].

The social KPIs are identified as belonging to two different stakeholders of both healthcare system and IT system. The former are social indicators investigating the side of the patient, the latter are those that can be seen on the side of the staff, be it managerial, medical or paramedical.

On the patient side, the most relevant KPIs are those investigating the health status and overall satisfaction, complaints and safety of these stakeholders. The already mentioned EMR, telemedicine and e-health system extend the possibilities of monitoring the health status of the population by collecting and processing data and exchanging them via networks and IT infrastructures. At the same time, these systems allow information to be collected about patient satisfaction with healthcare service, their complaints, their safety within the healthcare structures or during treatments, helping to avoid human errors, wrong diagnosis or delays. Most providers agree that a simple way to reduce prescription errors is to use digital entries rather than handwritten scripts [121].

On the staff side, it was recently investigated how IT (directly and indirectly) can improve employee satisfaction with their job [122-124]. Access to records and data is easier and more efficient and multidisciplinary collaboration mediated by IT infrastructures [125] is an emerging and powerful source of knowledge. 
Last but not least, some environmental variables are introduced to assess the sustainability of IT in healthcare, also in this area. It has already been mentioned how the use of EMR can increase the efficiency of information retrieval and the cooperation and data sharing among different healthcare structures. The immediate availability of comprehensive information on patients' health status can reduce the number of low-productivity medical visits, while achieving more with fewer visits [126]. Specific studies [127] have shown that these new technologies lead to a rate of $9 \%$ to $26 \%$ for avoided transportation, thus greatly reducing the emissions of carbon dioxide. Online requests for mailed prescription refills also contribute to a substantial decrease of carbon dioxide emissions.

Specific IT paradigms such as Grid, Cloud and Collaborative Computing could also help to reduce energy consumption. Grid computing has succeeded somewhat in enabling the sharing of resources across organizations but was not widespread due to its complex implementation and interface. Cloud computing overcomes this aspect by enabling simple and easy user access, meeting the dynamic and elastic needs of users, providing metered usage for its resources and therefore is increasingly being adopted by individual users as well as enterprise users. The Cloud, therefore, seems to be a very interesting technology for the IT infrastructure in healthcare [128-130].

Another important aspect of EMR and-more generally-of IT applied to recording/classification of medical data is the potential saving of physical (often limited) resources [34]. EMR could reduce the use of paper, ledgers, dedicated rooms, while e-health and some forms of e-learning can (partially) replace the use of dedicated rooms and books. The already discussed increase in efficiency in cooperation and teamwork and the increasing potential of telemedicine and e-health potentially reduce the need of transporting doctors and patients and of duplicating resources and physical materials.

\section{Managerial and Practical Implications for the Framework}

The purpose of this paragraph is to discuss how the HCC-MOTES framework could provide guidance to managerial decision making in healthcare companies. As already emphasized, the model is derived from the analysis and differential study of literature on several different fields, so that it represents both an empirical generalization and a focus on the core aspects of IT in healthcare. This was a key objective of the approach, which allows healthcare policy makers to use a single model, instead of necessarily using multiple sets, having to select some indicators and/or discard others.

In other worlds, the purpose of the framework is to help evaluate a number of IT alternatives that influence these various factors. Managerial decision making in healthcare domain is, in fact, a multifaceted and complex task, as it must take into account economical/financial/organizational aspects, as well as social/environmental ones [131-133]. For this reason, several methodologies have been discussed for determining the qualitative composition of an expert group and the weighting factor regarding the importance of expert's judgments for the purpose of participating in decision-making in the healthcare domain [134]. This is particularly crucial for IT adoption, where technological topics are as important as economic and social ones [135].

This is where the HCC-MOTES framework could offer a support, when having to invest in IT, the model can be applied to the healthcare structure in order to:

(1) Better understand the current status of IT in the given system and its connections with other areas

(2) Better assess what could (or should) be improved, given specific priorities and aims

In other words, the framework can facilitate the task of studying the current ("as-is") status of the system, comparing different parts of the same structure or even different structures, finding limits, better understand competitive advantages and so forth. The application of the HCC-MOTES framework can be extended to company functions, departments and also to individual projects, so that the model can be used to evaluate and describe individual and specific IT application projects but also their effects on the overall structure.

Based on the area to be prioritized, the framework can then be used, sequentially and iteratively, for a target ("to-be") analysis. For example, some of the social aspects can be considered first, aiming 
to improve the patients' satisfaction while minimizing their discomfort and complaints. Consequently, some of the managerial/organizational aspects should be considered next, in order to understand how the specific IT system should affect the organizational efficiency. Next, the technological aspect could be considered, by analytically studying the performance and accessibility of the system. Last but not least, the environmental variables must be taken into account, in order to evaluate the energy consumption of the system and the possible savings in physical resources used with this approach. Overall, the decision maker will have a snapshot of the situation and also some figures about the total expenditure required, the possible monetary savings, the enhancements in social sustainability and so on.

Simulation tools could be used along with the framework (and according to it), in order to analytically but virtually, design a subset of the IT system within specific healthcare structure, by creating a kind of "digital twin" [136,137]. This would allow a what-if analysis [138,139], driven by the HCC-MOTES set of indicators.

At this stage of the theory development, the framework lacks associated units of measurement, making it more of a template than the final system of measurement and strategic management for IT within healthcare. However, this framework is a strategic and comprehensive tool for healthcare management, that can be used to monitor and steer specific IT projects and general efforts to improve performance, efficiency and social and environmental aspects.

Figure 2 proposes an example of a use case to illustrate a flow of managerial decisions/implications, all directly linked to IT strategies within a healthcare structure. The links are potentially biunivocal.

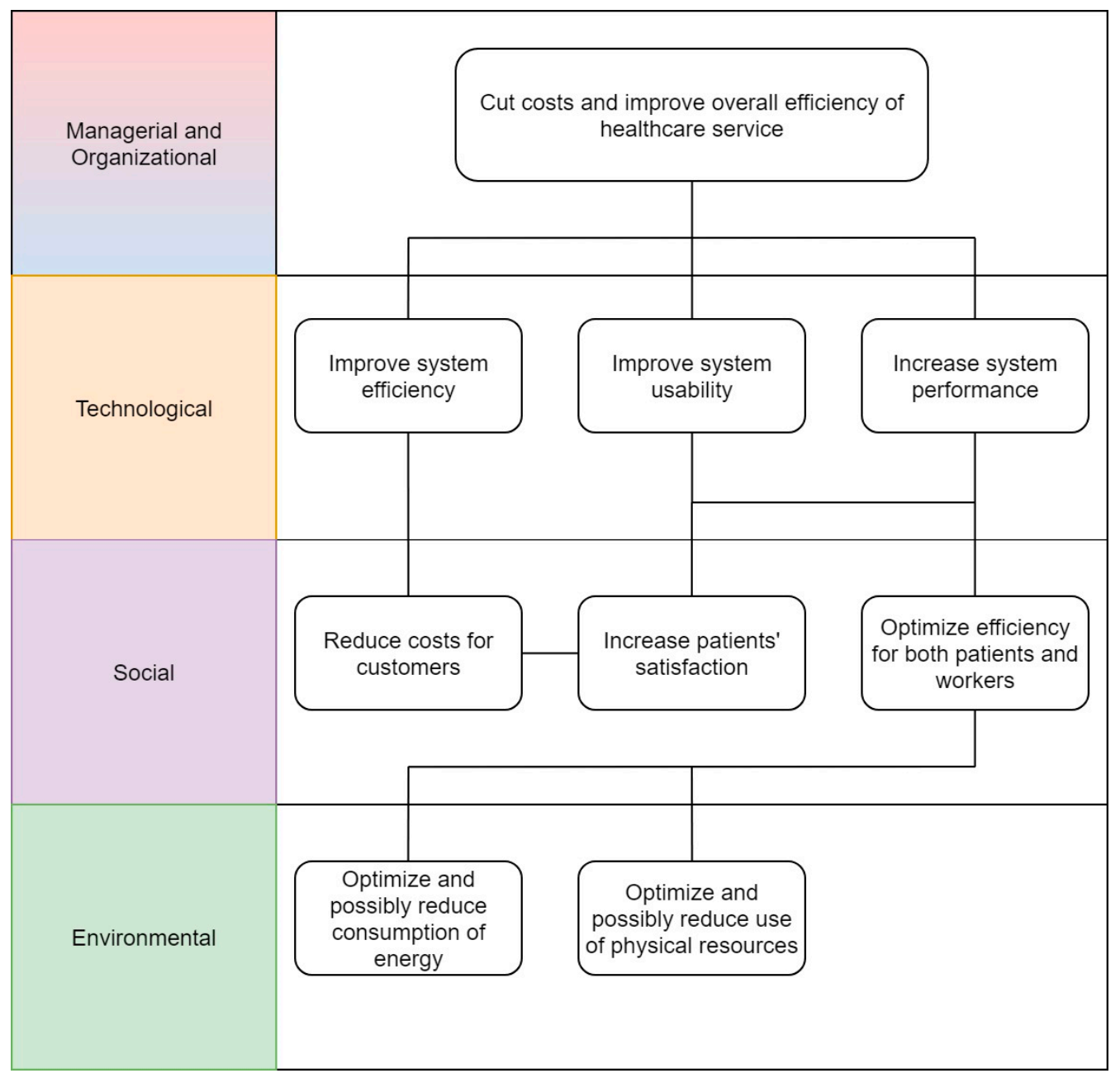

Figure 2. Example of a use case for the application of the HCC-MOTES framework as a managerial decision support tool. There is not a specific order for the flow and the links are potentially biunivocal. 


\section{Conclusions and Future Directions}

The question research of the present work was to understand, by means of literature review and case studies, whether and how the introduction of IT could be regarded as a source of sustainability for healthcare and, specifically, in which areas and domains. The evidence collected from literature points towards financial and economical savings as an immediate consequence but also to organizational changes and, more importantly, given the specific field, to social benefits in term of more effective treatments for patients, fewer human errors in therapies, better teamwork and cooperation for doctors and healthcare structures and, overall, a better assessment of healthcare systems.

Given these potential (and actual) benefits, the second purpose of this research was to identify a set of metrics, inspired by and to sustainability as a science, that are capable of representing and possibly evaluating specific healthcare IT projects. The aim is, therefore, to advance the literature about healthcare with a framework capable of unifying and bringing together both the managerial and organizational literature and the technological one, with the common goal of analysing the sustainability and efficiency-in different areas-of IT applied to healthcare. Several indicators already exist, to evaluate the performance of a healthcare structure or the performance of a software and, more generally, of an IT system. However, there is no comprehensive set of indicator to assess and evaluate the sustainability of IT applied to healthcare, that takes several different but potentially related areas, into account.

For this reason, partly inspired by the multidisciplinary literature analysed and by existing and validated sets of metrics, a novel set of indicators is presented in this work, taking into account five main dimensions: Managerial, Organizational, Technological, Environmental and Social (MOTES), each of which explores several of the sustainability implications of an IT project, specifically applied to the healthcare sector. The framework might take into account a number of other factors and decision criteria but the complexity of the decision-making environment would increase. Although increasing complexity is more realistic, it usually requires additional effort to obtain the preferences of decision-makers and more complex data. The trade-off between the time taken to make decisions and the realism of the model must also be taken into account.

The main limitation of the proposed set is that it is mainly qualitative. However, it can be used to study and classify IT projects where healthcare management wants a comprehensive picture of the impact of the proposed innovation. Nevertheless, it could be a guideline for decision makers who need to implement or update an IT system in healthcare domain, by taking into account several dimensions and their specificity. Future field studies must be carried out to determine whether the proposed perspectives are necessary and appropriate and, where possible, to determine appropriate measures.

Another limitation is that this set is, for now, theoretical, that is, it has not yet been applied to any hospital or clinic; the novel set has been discussed with some doctors working in private clinics and/or hospitals, as well as with some IT managers and a chief medical officer, who all found it interesting, innovative and potentially useful as a set of guidelines and as a decision support tool. This is not exhaustive to claim and argue that the present framework can be used "as it is" and on a large scale but along with the fact that it is partially based on other existing-and validated-sets, it suggests that it is ready for specific validation and pilot tests.

In qualitative models, substantial validation includes self-reflection in order to assess one's own understanding of the subject as a researcher and how this may influence the interpretation of the data. Ethical validation requires research to provide practical answers to research questions that have transformative value and lead to actions and impacts, such as effective interventions on health issues.

The reliability of qualitative research is then ensured by accurate data recording, transcription and/or tuning [140]. Here, too, the positive influence of IT resources on the capabilities of organizations has been empirically confirmed and validated [109] and the same needs to be done to the presented novel framework for the healthcare system. Future work on this topic will also propose a quantitative simulation tool (discrete process simulation) to analyse specific BPR, due to IT introduction, on a what-if basis. HCC-MOTES metrics will be used to rank and classify IT projects in this context. 
Conflicts of Interest: The author declares no conflict of interest.

\section{References}

1. Robinson, R. Cost-benefit analysis. BMJ 1993, 307, 924-926. [CrossRef] [PubMed]

2. Layard, P.R.G. Cost-Benefit Analysis; Cambridge University Press: Cambridge, UK, 1994.

3. Quah, E.; Haldane, J.B.S. Cost-Benefit Analysis; Routledge: Abingdon, UK, 2007.

4. Kuhlman, T.; Farrington, J. What is Sustainability? Sustainability 2010, 2, 3436-3448. [CrossRef]

5. Atkinson, G.; Mourato, S. Cost-Benefit Analysis and The Environment: Recent Developments; The National Academies of Sciences: Washington, DC, USA, 2006.

6. Karlsson, C. Cost-Benefit Analysis in Healthcare. 2016. Available online: http://lup.lub.lu.se/luur/download? func $=$ downloadFile\&recordOId $=8892303 \&$ fileOId $=8892304$ (accessed on 30 July 2018).

7. Drucker, P.F. The discipline of innovation. Harv. Bus. Rev. 1985, 63, 67-72. [CrossRef] [PubMed]

8. Konsynski, B.R. Process innovation: Reengineering work through information technology. MIT Sloan Manag. Rev. 1993, 34, 99.

9. Baregheh, A.; Rowley, J.; Sambrook, S. Towards a multidisciplinary definition of innovation. Manag. Decis. 2009, 47, 1323-1339. [CrossRef]

10. Rothwell, R. Industrial innovation: Success, strategy, trends. In The Handbook of Industrial Innovation; Edward Elgar Publishing: Cheltenham, UK, 1995.

11. Burke, W.W. Organization Change: Theory and Practice; Sage Publications: Thousand Oaks, CA, USA, 2017.

12. Cavalluzzo, K.S.; Ittner, C.D. Implementing performance measurement innovations: Evidence from government. Account. Organ. Soc. 2004, 29, 243-267. [CrossRef]

13. Chan, F.T.; Qi, H.J. An innovative performance measurement method for supply chain management. Supply Chain Manag. Int. J. 2003, 8, 209-223. [CrossRef]

14. Ittner, C.D.; Larcker, D.F. Innovations in performance measurement: Trends and research implications. J. Manag. Account. Res. 1998, 10, 205.

15. Kaplan, R.S.; Norton, D.P. Transforming the balanced scorecard from performance measurement to strategic management: Part I. Account. Horiz. 2001, 15, 87-104. [CrossRef]

16. Boons, F.; Lüdeke-Freund, F. Business models for sustainable innovation: State-of-the-art and steps towards a research agenda. J. Clean. Prod. 2013, 45, 9-19. [CrossRef]

17. Barile, S.; Saviano, M.; Iandolo, F. L'innovazione tra creatività e sostenibilità. In Immaginare L'innovazione; Giappichelli: Torino, Italy, 2012; ISBN 9788834838747.

18. Ashford, N.A.; Hall, R.P. The importance of regulation-induced innovation for sustainable development. Sustainability 2011, 3, 270-292. [CrossRef]

19. Schilling, M.A. Strategic Management of Technological Innovation; Tata McGraw-Hill Education: New York, NY, USA, 2010.

20. Von Hippel, E. The sources of innovation. In Das Summa Summarum des Management; Springer: Berlin, Germany, 2007; pp. 111-120.

21. Yam, R.C.; Lo, W.; Tang, E.P.; Lau, A.K. Analysis of sources of innovation, technological innovation capabilities, and performance: An empirical study of Hong Kong manufacturing industries. Res. Policy 2011, 40, 391-402. [CrossRef]

22. Venkatesh, V.; Morris, M.G.; Davis, G.B.; Davis, F.D. User acceptance of information technology: Toward a unified view. MIS Q. 2003, 27, 425-478. [CrossRef]

23. Bocij, P.; Greasley, A.; Hickie, S. Business Information Systems: Technology, Development and Management; Pearson Education: London, UK, 2008.

24. Gunasekaran, A.; Ngai, E.W. Information systems in supply chain integration and management. Eur. J. Oper. Res. 2004, 159, 269-295. [CrossRef]

25. Hamelink, C.J. New Information and Communication Technologies, Social Development and Cultural Change; United Nations Research Institute for Social Development Geneva: Geneva, Switzerland, 1997; Volume 86.

26. Fichman, R.G. Going beyond the dominant paradigm for information technology innovation research: Emerging concepts and methods. J. Assoc. Inf. Syst. 2004, 5, 11. [CrossRef]

27. Land, F. The Social Study of Information and Communication Technology: Innovation, Actors, and Contexts; Oxford University Press: Oxford, UK, 2004. 
28. Davenport, T.H.; Short, J.E. The new industrial engineering: Information technology and business process redesign. MIT Sloan Manag. Rev. 1990, 31, 11.

29. Attaran, M. Exploring the relationship between information technology and business process reengineering. Inf. Manag. 2004, 41, 585-596. [CrossRef]

30. Erek, K.; Schmidt, N.-H.; Zarnekow, R.; Kolbe, L.M. Sustainability in information systems: Assortment of current practices in IS organizations. In Proceedings of the AMCIS 2009, San Francisco, CA, USA, 6-9 August 2009; p. 123.

31. Bengtsson, F.; Ågerfalk, P.J. Information technology as a change actant in sustainability innovation: Insights from Uppsala. J. Strateg. Inf. Syst. 2011, 20, 96-112. [CrossRef]

32. Chen, A.J.; Boudreau, M.-C.; Watson, R.T. Information systems and ecological sustainability. J. Syst. Inf. Technol. 2008, 10, 186-201. [CrossRef]

33. Melville, N.P. Information systems innovation for environmental sustainability. MIS Q. 2010, 34, 1-21. [CrossRef]

34. Hilty, L.M.; Aebischer, B. Ict for sustainability: An emerging research field. In ICT Innovations for Sustainability; Springer: Berlin, Germany, 2015; pp. 3-36.

35. Powell, T.C.; Dent-Micallef, A. Information technology as competitive advantage: The role of human, business, and technology resources. Strateg. Manag. J. 1997, 18, 375-405. [CrossRef]

36. Stewart, T.; Ruckdeschel, C. Intellectual Capital: The New Wealth of Organizations; Wiley Online Library: Hoboken, NJ, USA, 1998.

37. Iqbal, N.; Nadeem, W.; Zaheer, A. Impact of BPR critical success factors on inter-organizational functions: An empirical study. Bus. Manag. Rev. 2015, 6, 152.

38. Dave, B. Business process management-a construction case study. Constr. Innov. 2017, 17, 50-67. [CrossRef]

39. Wang, P. Whatever Happened to Business Process Reengineering? The Rise, Fall, and Possible Revival of Business Process Reengineering from the Organizing Vision Perspective. In Business Process Transformation; Routledge: Abingdon, UK, 2015; pp. 39-56.

40. Serban, A.I. Managing Transformation: Business Process Reengineering or Total Quality Management. Int. J. Acad. Res. Bus. Soc. Sci. 2015, 5, 81-86. [CrossRef]

41. Kim, K.K.; Michelman, J.E. An examination of factors for the strategic use of information systems in the healthcare industry. MIS Q. 1990, 14, 201-215. [CrossRef]

42. Global Reporting Initiative. Sustainability Reporting Guidelines on Economic, Environmental and Social Performance; Global Reporting Initiative: Amsterdam, The Netherlands, 2000.

43. Finkbeiner, M.; Schau, E.M.; Lehmann, A.; Traverso, M. Towards Life Cycle Sustainability Assessment. Sustainability 2010, 2, 3309-3322. [CrossRef]

44. Mehta, N.; Ni, J.; Srinivasan, K.; Sun, B. A Dynamic Model of Health Insurance Choices and Healthcare Consumption Decisions. Mark. Sci. 2017, 36, 338-360. [CrossRef]

45. Pekerti, A.; Vuong, Q.-H.; Ho, T.M.; Vuong, T.-T. Health Care Payments in Vietnam: Patients' Quagmire of Caring for Health versus Economic Destitution. Int. J. Environ. Res. Public. Health 2017, 14, 1118. [CrossRef] [PubMed]

46. Nuti, S. Il Sistema di Valutazione della Performance in Sanità; Il Mulino: Bologna, Italy, 2008; ISBN 978-88-15-12427-2.

47. Nielsen, J.; Molich, R. Heuristic evaluation of user interfaces. In Proceedings of the SIGCHI Conference on Human Factors in Computing Systems, Washington, DC, USA, 1-5 April 1990; Association for Computing Machinery: New York, NY, USA, 1990; pp. 249-256.

48. Sørensen, K.; Van den Broucke, S.; Fullam, J.; Doyle, G.; Pelikan, J.; Slonska, Z.; Brand, H. Health literacy and public health: A systematic review and integration of definitions and models. BMC Public Health 2012, 12, 80. [CrossRef] [PubMed]

49. Starfield, B. Is primary care essential? Lancet 1994, 344, 1129-1133. [CrossRef]

50. Wendt, C.; Frisina, L.; Rothgang, H. Healthcare system types: A conceptual framework for comparison. Soc. Policy Adm. 2009, 43, 70-90. [CrossRef]

51. Lorenzoni, L.; Belloni, A.; Sassi, F. Health-care expenditure and health policy in the USA versus other high-spending OECD countries. Lancet 2014, 384, 83-92. [CrossRef]

52. Unger, F. Health is wealth: Considerations to European healthcare. Prilozi 2012, 33, 9-14. [PubMed]

53. Mossialos, E.; Wenzl, M.; Osborn, R.; Sarnak, D. 2015 International Profiles of Health Care Systems; Canadian Agency for Drugs and Technologies in Health: Ottawa, ON, Canada, 2016. 
54. Curto, V.; Einav, L.; Finkelstein, A.; Levin, J.D.; Bhattacharya, J. Healthcare Spending and Utilization in Public and Private Medicare; National Bureau of Economic Research: Cambridge, MA, USA, 2017.

55. Dexheimer Neto, F.L.; Rosa, R.G.; Duso, B.A.; Haas, J.S.; Savi, A.; Cabral, C.D.R.; Maccari, J.G.; de Oliveira, R.P.; Antônio, A.C.P.; Castro, P.D.S.; et al. Public versus private healthcare systems following discharge from the ICU: A propensity score-matched comparison of outcomes. BioMed Res. Int. 2016, 2016, 6568531. [CrossRef] [PubMed]

56. Uyar, A.; Neyis, A. Does the healthcare industry report quality costs? Comparative investigations of public and private hospitals. Total Qual. Manag. Bus. Excell. 2015, 26, 733-745. [CrossRef]

57. Magee, H.; Davis, L.-J.; Coulter, A. Public views on healthcare performance indicators and patient choice. J. R. Soc. Med. 2003, 96, 338-342. [CrossRef] [PubMed]

58. Bonbright, J.C.; Danielsen, A.L.; Kamerschen, D.R. Principles of Public Utility Rates; Columbia University Press: New York, NY, USA, 1961.

59. Porter, M.E.; Kramer, M.R. Creating Shared Value. In Managing Sustainable Business; Springer: Dordrecht, The Netherlands, 2019; pp. 327-350. ISBN 978-94-024-1142-3.

60. De Raeve, P.; Gomez, S.; Hughes, P.; Lyngholm, T.; Sipilä, M.; Kilanska, D.; Hussey, P.; Xyrichis, A.; ENS4Care project. Enhancing the provision of health and social care in Europe through eH ealth. Int. Nurs. Rev. 2017, 64, 33-41. [CrossRef] [PubMed]

61. Sieck, C.J.; McAlearney, A.S. Integrated care and eHealth tools in the US and Europe: Editorial response to "eHealth in integrated care programs for people with multimorbidity in Europe: Insights from the ICARE4EU project". J. Hosp. Manag. Health Policy 2018. [CrossRef]

62. Ben-Assuli, O. Electronic health records, adoption, quality of care, legal and privacy issues and their implementation in emergency departments. Health Policy 2015, 119, 287-297. [CrossRef] [PubMed]

63. Hoffman, S.; Podgurski, A. Finding a cure: The case for regulation and oversight of electric health record systems. Harv. JL Tech. 2008, 22, 103.

64. Dahlgaard, J.J.; Pettersen, J.; Dahlgaard-Park, S.M. Quality and lean health care: A system for assessing and improving the health of healthcare organisations. Total Qual. Manag. Bus. Excell. 2011, 22, 673-689. [CrossRef]

65. Shohet, I.M. Key performance indicators for strategic healthcare facilities maintenance. J. Constr. Eng. Manag. 2006, 132, 345-352. [CrossRef]

66. Sheikh, A.; Sood, H.S.; Bates, D.W. Leveraging health information technology to achieve the "triple aim" of healthcare reform. J. Am. Med. Inform. Assoc. 2015, 22, 849-856. [CrossRef] [PubMed]

67. Cinquini, L.; Nuti, S.; Boccaccio, A.; Vainieri, M. Il confronto di performance economico-finanziarie tra aziende sanitarie: L'esperienza della Regione Toscana. Mecosan 14 2005, 54, 109-130.

68. Nuti, S. Il Sistema di Valutazione Della Performance Della Sanità Toscana-Report 2009; Edizioni ETS: Pisa, Italy, 2010.

69. Murante, A.M.; Panero, C.; Nuti, S. L'esperienza dei cittadini del servizio di medicina generale: Come la comunicazione influenza la relazione medico-paziente. Quattro regioni a confronto. In VIII Congresso Nazionale CARD; Sant'Anna School of Advanced Studies: Pisa, Italy, 2010; pp. 16-18.

70. Blumenthal, D. Stimulating the adoption of health information technology. N. Engl. J. Med. 2009, 360, 1477-1479. [CrossRef] [PubMed]

71. Anyanwu, K.; Sheth, A.; Cardoso, J.; Miller, J.; Kochut, K. Healthcare enterprise process development and integration. J. Res. Pract. Inf. Technol. 2003, 35, 83.

72. Lenz, R.; Reichert, M. IT support for healthcare processes-Premises, challenges, perspectives. Data Knowl. Eng. 2007, 61, 39-58. [CrossRef]

73. Doorslaer, E.V.; Wagstaff, A.; Rutten, F. Equity in the Finance and Delivery of Health Care: An International Perspective; Oxford University Press: Oxford, UK, 1992.

74. La Rosa-Salas, V.; Tricas-Sauras, S. Equity in health care. Cuad. Bioet. 2008, 19, 355-368. [PubMed]

75. Katz, M.L.; Shapiro, C. Network externalities, competition, and compatibility. Am. Econ. Rev. 1985, 75, 424-440.

76. Chetley, A.; Davies, J.; Trude, B.; McConnell, H.; Ramirez, R. Improving Health Connecting People: The Role of ICTs in the Health Sector of Developing Countries. 2006. Available online: https:/ / www.popline.org/ node/185203 (accessed on 10 May 2018).

77. Hoque, M.R.; Bao, Y.; Sorwar, G. Investigating factors influencing the adoption of e-Health in developing countries: A patient's perspective. Inform. Health Soc. Care 2017, 42, 1-17. [CrossRef] [PubMed] 
78. Lloyd, J.; Wait, S. Integrated Care: A Guide for Policymakers. 2006. Available online: https://www.popline. org/node/175307 (accessed on 18 May 2018).

79. Payne, T.H.; Corley, S.; Cullen, T.A.; Gandhi, T.K.; Harrington, L.; Kuperman, G.J.; Mattison, J.E.; McCallie, D.P.; McDonald, C.J.; Tang, P.C. Report of the AMIA EHR-2020 Task Force on the status and future direction of EHRs. J. Am. Med. Inform. Assoc. 2015, 22, 1102-1110. [CrossRef] [PubMed]

80. Acerete, B.; Stafford, A.; Stapleton, P. Spanish healthcare public private partnerships: The 'Alzira model'. Crit. Perspect. Account. 2011, 22, 533-549. [CrossRef]

81. Shukla, R.; Shatrugna, V.; Srivatsan, R. Aarogyasri healthcare model: Advantage private sector. Econ. Political Wkly. 2011, 46, 38-42.

82. Muhsin, B.; Sampath, A.; Gruber, T. Systems and Methods for Storing, Analyzing, Retrieving and Displaying Streaming Medical Data. U.S. Patent 9,142,117, 22 September 2015.

83. Zhang, Y.; Qiu, M.; Tsai, C.-W.; Hassan, M.M.; Alamri, A. Health-CPS: Healthcare cyber-physical system assisted by cloud and big data. IEEE Syst. J. 2017, 11, 88-95. [CrossRef]

84. Agha, L. The effects of health information technology on the costs and quality of medical care. J. Health Econ. 2014, 34, 19-30. [CrossRef] [PubMed]

85. Jones, S.S.; Rudin, R.S.; Perry, T.; Shekelle, P.G. Health information technology: An updated systematic review with a focus on meaningful use. Ann. Intern. Med. 2014, 160, 48-54. [CrossRef] [PubMed]

86. Hillestad, R.; Bigelow, J.; Bower, A.; Girosi, F.; Meili, R.; Scoville, R.; Taylor, R. Can electronic medical record systems transform health care? Potential health benefits, savings, and costs. Health Aff. (Millwood) 2005, 24, 1103-1117. [CrossRef] [PubMed]

87. Ruxwana, N.L.; Herselman, M.E.; Conradie, D.P. ICT Applications as E-Health Solutions in Rural Healthcare in the Eastern Cape Province of South Africa, ICT Applications as E-Health Solutions in Rural Healthcare in the Eastern Cape Province of South Africa. Health Inf. Manag. J. 2010, 39, 17-29. [CrossRef]

88. Ariani, A.; Koesoema, A.P.; Soegijoko, S. Innovative Healthcare Applications of ICT for Developing Countries. In Innovative Healthcare Systems for the 21st Century; Understanding Complex Systems; Springer: Cham, Switzerland, 2017; pp. 15-70. ISBN 978-3-319-55773-1.

89. Chaudhry, B.; Wang, J.; Wu, S.; Maglione, M.; Mojica, W.; Roth, E.; Morton, S.C.; Shekelle, P.G. Systematic review: Impact of health information technology on quality, efficiency, and costs of medical care. Ann. Intern. Med. 2006, 144, 742-752. [CrossRef] [PubMed]

90. Sun, X.; Chen, Y.; Tong, X.; Feng, Z.; Wei, L.; Zhou, D.; Tian, M.; Lv, B.; Feng, D. The use of annual physical examinations among the elderly in rural China: A cross-sectional study. BMC Health Serv. Res. 2014, 14, 16. [CrossRef] [PubMed]

91. Yeo, J.-Y.; Jeong, H.-S. Determinants of health screening and its effects on health behaviors. Health Policy Manag. 2012, 22, 49-64. [CrossRef]

92. Wong, H.Z.; Lim, W.-Y.; Ma, S.S.; Chua, L.A.; Heng, D.M. Health Screening Behaviour among Singaporeans. Ann. Acad. Med. 2015, 44, 326-334.

93. Vuong, Q.-H.; Ho, T.-M.; Nguyen, H.-K.; Vuong, T.-T. Healthcare consumers' sensitivity to costs: A reflection on behavioural economics from an emerging market. Palgrave Commun. 2018, 4, 70. [CrossRef]

94. Akin, J.; Birdsall, N.; de Ferranti, D. Financing Health Services in Developing Countries: An Agenda for Reform; The World Bank: Washington, DC, USA, 1986.

95. Whitehead, M.; Dahlgren, G.; Evans, T. Equity and health sector reforms: Can low-income countries escape the medical poverty trap? Lancet 2001, 358, 833-836. [CrossRef]

96. Cassels, A. Health sector reform: Key issues in less developed countries. J. Int. Dev. 1995, 7, 329-347. [CrossRef] [PubMed]

97. Lucas, H. Information and communications technology for future health systems in developing countries. Soc. Sci. Med. 2008, 66, 2122-2132. [CrossRef] [PubMed]

98. Blaya, J.A.; Fraser, H.S.F.; Holt, B. E-Health Technologies Show Promise in Developing Countries. Health Aff. (Millwood) 2010, 29, 244-251. [CrossRef] [PubMed]

99. Vuong, Q.-H. The (ir)rational consideration of the cost of science in transition economies. Nat. Hum. Behav. 2018, 2, 5. [CrossRef]

100. Toor, S.-R.; Ogunlana, S.O. Beyond the 'iron triangle': Stakeholder perception of key performance indicators (KPIs) for large-scale public sector development projects. Int. J. Proj. Manag. 2010, 28, 228-236. [CrossRef] 
101. Dewett, T.; Jones, G.R. The role of information technology in the organization: A review, model, and assessment. J. Manag. 2001, 27, 313-346. [CrossRef]

102. Melville, N.; Kraemer, K.; Gurbaxani, V. Information technology and organizational performance: An integrative model of IT business value. MIS Q. 2004, 28, 283-322. [CrossRef]

103. Bass, L.; Clements, P.; Kazman, R. Software Architecture in Practice; Addison-Wesley Professional: Boston, MA, USA, 2003.

104. Albertao, F.; Xiao, J.; Tian, C.; Lu, Y.; Zhang, K.Q.; Liu, C. Measuring the sustainability performance of software projects. In Proceedings of the 2010 IEEE 7th International Conference on e-Business Engineering (ICEBE), Shanghai, China, 10-12 November 2010; IEEE: Piscataway, NJ, USA, 2010; pp. 369-373.

105. Si, S.-L.; You, X.-Y.; Liu, H.-C.; Huang, J. Identifying key performance indicators for holistic hospital management with a modified DEMATEL approach. Int. J. Environ. Res. Public Health 2017, 14, 934. [CrossRef] [PubMed]

106. Wen, C.L. Telemedicine, eHealth and Remote Care Systems. In Global Health Informatics; Elsevier: New York, NY, USA, 2017; pp. 168-194.

107. Ozcan, Y.A.; Luke, R.D.; Haksever, C. Ownership and Organizational Performance: A Comparison of Technical Efficiency across Hospital Types. Med. Care 1992, 30, 781-794. [CrossRef] [PubMed]

108. Hussey, P.S.; de Vries, H.; Romley, J.; Wang, M.C.; Chen, S.S.; Shekelle, P.G.; McGlynn, E.A. A Systematic Review of Health Care Efficiency Measures. Health Serv. Res. 2009, 44, 784-805. [CrossRef] [PubMed]

109. Wu, S.P.-J.; Straub, D.W.; Liang, T.-P. How information technology governance mechanisms and strategic alignment influence organizational performance: Insights from a matched survey of business and IT managers. Mis Q. 2015, 39, 497-518. [CrossRef]

110. Hedley, T.P. Measuring public sector effectiveness using private sector methods. Public Product. Manag. Rev. 1998, 21, 251-258. [CrossRef]

111. Gapenski, L.C.; Pink, G.H. Understanding Healthcare Financial Management; Health Administration Press: Chicago, IL, USA, 2007.

112. Karam, M.; Brault, I.; Van Durme, T.; Macq, J. Comparing interprofessional and interorganizational collaboration in healthcare: A systematic review of the qualitative research. Int. J. Nurs. Stud. 2018, 79, 70-83. [CrossRef] [PubMed]

113. Svensson, A.; Larsson, L.; Hansson, A. IT Systems for Collaboration in Healthcare for Frail Elderly People. In Proceedings of the European Conference on Knowledge Management, Coleraine, UK, 1-2 September 2016; p. 859.

114. Radhakrishna, K.; Goud, B.R.; Kasthuri, A.; Waghmare, A.; Raj, T. Electronic health records and information portability: A pilot study in a rural primary healthcare center in India. Perspect. Health Inf. Manag. 2014, 11, 1b. [PubMed]

115. Kushniruk, A.W.; Borycki, E.M.; Kuwata, S.; Kannry, J. Emerging approaches to usability evaluation of health information systems: Towards in-situ analysis of complex healthcare systems and environments. Stud. Health Technol. Inform. 2011, 169, 915-919. [PubMed]

116. Sarnikar, S.; Murphy, M. A Usability Analysis Framework for Healthcare Information Technology. Int. J. Technol. Diffus. IJTD 2012, 3, 20-28. [CrossRef]

117. Marschollek, M.; Mix, S.; Wolf, K.-H.; Effertz, B.; Haux, R.; Steinhagen-Thiessen, E. ICT-based health information services for elderly people: Past experiences, current trends, and future strategies. Med. Inform. Internet Med. 2007, 32, 251-261. [CrossRef] [PubMed]

118. Kari, H.K. Availability and accessibility of ICT in the rural communities of Nigeria. Electron. Libr. 2007, 25, 363-372. [CrossRef]

119. McNulty, T.; Ferlie, E. Process transformation: Limitations to radical organizational change within public service organizations. Organ. Stud. 2004, 25, 1389-1412. [CrossRef]

120. Buccoliero, L.; Bellio, E.; Mazzola, M.; Solinas, E. Technology innovation in healthcare and changing patient's behaviors: New challenges for marketing. Mercati E Compet. 2016, 1, 45-70. [CrossRef]

121. Raghupathi, W.; Raghupathi, V. Big data analytics in healthcare: Promise and potential. Health Inf. Sci. Syst. 2014, 2, 3. [CrossRef] [PubMed]

122. Limbu, Y.B.; Jayachandran, C.; Babin, B.J. Does information and communication technology improve job satisfaction? The moderating role of sales technology orientation. Ind. Mark. Manag. 2014, 43, 1236-1245. [CrossRef] 
123. Chumg, H.-F.; Cooke, L.; Fry, J.; Hung, I.-H. Factors affecting knowledge sharing in the virtual organisation: Employees' sense of well-being as a mediating effect. Comput. Hum. Behav. 2015, 44, 70-80. [CrossRef]

124. Tarute, A.; Gatautis, R. ICT impact on SMEs performance. Procedia-Soc. Behav. Sci. 2014, 110, 1218-1225. [CrossRef]

125. Olaniran, B.A. ICTs, E-health, and Multidisciplinary Healthcare Teams: Promises and Challenges. Int. J. Priv. Health Inf. Manag. IJPHIM 2016, 4, 62-75. [CrossRef]

126. Garrido, T.; Jamieson, L.; Zhou, Y.; Wiesenthal, A.; Liang, L. Effect of electronic health records in ambulatory care: Retrospective, serial, cross sectional study. BMJ 2005, 330, 581. [CrossRef] [PubMed]

127. Turley, M.; Porter, C.; Garrido, T.; Gerwig, K.; Young, S.; Radler, L.; Shaber, R. Use of Electronic Health Records Can Improve the Health Care Industry's Environmental Footprint. Health Aff. (Millwood) 2011, 30, 938-946. [CrossRef] [PubMed]

128. Hoang, D.B.; Chen, L. Mobile Cloud for Assistive Healthcare (MoCAsH). In Proceedings of the 2010 IEEE Asia-Pacific Services Computing Conference, Hangzhou, China, 6-10 December 2010; pp. 325-332.

129. Sultan, N. Making use of cloud computing for healthcare provision: Opportunities and challenges. Int. J. Inf. Manag. 2014, 34, 177-184. [CrossRef]

130. Remondino, M. Analisi strategica del modello cloud, inteso come possibile innovazione di servizio e di processo per le imprese. Impresa Progetto-Electron. J. Manag. 2013, 2. Available online: https:/ /www.impresaprogetto.it/ sites/impresaprogetto.it/files/articles/2-2013_wp_remondino.pdf (accessed on 30 July 2018).

131. Eichler, H.-G.; Kong, S.X.; Gerth, W.C.; Mavros, P.; Jönsson, B. Use of cost-effectiveness analysis in health-care resource allocation decision-making: How are cost-effectiveness thresholds expected to emerge? Value Health 2004, 7, 518-528. [CrossRef] [PubMed]

132. Shapira, Z. Organizational Decision Making; Cambridge University Press: Cambridge, UK, 2002.

133. Walshe, K.; Rundall, T.G. Evidence-based management: From theory to practice in health care. Milbank Q. 2001, 79, 429-457. [CrossRef] [PubMed]

134. Ivlev, I.; Kneppo, P.; Barták, M. Method for Selecting Expert Groups and Determining the Importance of Expert's Judgments for the Purpose of Managerial Decision-Making Tasks in Health System; Technická univerzita v Liberci: Liberec, Czechia, 2015.

135. Huang, C.D.; Behara, R.S.; Goo, J. Optimal information security investment in a Healthcare Information Exchange: An economic analysis. Decis. Support Syst. 2014, 61, 1-11. [CrossRef]

136. Bruynseels, K.; Santoni de Sio, F.; van den Hoven, J. Digital twins in health care: Ethical implications of an emerging engineering paradigm. Front. Genet. 2018, 9, 31. [CrossRef] [PubMed]

137. Tao, F.; Sui, F.; Liu, A.; Qi, Q.; Zhang, M.; Song, B.; Guo, Z.; Lu, S.C.-Y.; Nee, A.Y.C. Digital twin-driven product design framework. Int. J. Prod. Res. 2018. [CrossRef]

138. Eason, K.D. Information Technology and Organisational Change; CRC Press: Boca Raton, FL, USA, 2014.

139. Marchewka, J.T. Information Technology Project Management; John Wiley \& Sons: Hoboken, NJ, USA, 2014.

140. Lewis, S. Qualitative inquiry and research design: Choosing among five approaches. Health Promot. Pract. 2015, 16, 473-475. [CrossRef]

(c) 2018 by the author. Licensee MDPI, Basel, Switzerland. This article is an open access article distributed under the terms and conditions of the Creative Commons Attribution (CC BY) license (http:// creativecommons.org/licenses/by/4.0/). 